\title{
COMPARATIVE ANALYSIS BETWEEN OSTEOSARCOMA AND EWING'S SARCOMA: EVALUATION OF THE TIME FROM ONSET OF SIGNS AND SYMPTOMS UNTIL DIAGNOSIS
}

\author{
Raquel Bezerra Guerra, Marcelo Duarte Tostes, Leandro da Costa Miranda, \\ Olavo Pires de Camargo, André Mathias Baptista, Marcelo Tadeu Caiero, Telma \\ Muria dos Santos Machado, Márcia Datz Abadi, Claudia Regina G.C.M Mendes \\ de Oliveira, and Renée Zon Filippi
}

Guerra RB, Tostes MD, Miranda L da C, de Camargo OP, Baptista AM, Caiero MT. Comparative analysis between Osteosarcoma and Ewing's sarcoma: evaluation of the time from onset of signs and symptoms until diagnosis. Clinics. 2006;61(2):99-106.

OBJECTIVE: The purposes of this study were to describe the early signs and symptoms of osteosarcoma and Ewing's sarcoma, identify symptoms that could be used to help differentiate the two types of tumors, and determine the time elapsed between the onset of signs and symptoms and the definitive diagnosis in our service, providing information and imputus for earlier diagnosis of these tumors.

METHODS: A retrospective analysis of the medical dossiers of 365 patients under 30 years of age diagnosed with osteosarcoma or Ewing's sarcoma was performed, and the aspects of the clinical diagnosis were statistically analyzed and compared.

RESULTS: The time between the onset of signs and the symptoms was 5.25 months for osteosarcoma and 8.1 months for Ewing's sarcoma, and the most frequent (89.5\%) early symptom of osteosarcoma and Ewing's sarcoma was local pain. Symptoms that might aid diagnosis included early local volume increase and the presence of fever.

CONCLUSION: The time until diagnosis of both neoplasias was higher than that reported for North America and Europe. Education of the lay public and medical professionals regarding suspicious early signs and symptoms might shorten the delay of diagnosis.

KEYWORDS: Ewing's sarcoma. Osteosarcoma. Bone neoplasias. Chemotherapy. Orthopedic surgery.

\section{INTRODUCTION}

Bone tumors are uncommon in adults, but they are the sixth most frequent group of neoplasic diseases among children and the third among adolescents, less frequent only than leukemias and lymphomas. ${ }^{1}$ Although osteosarcomas and Ewing's sarcomas are rare in the general population, they are the most frequently occurring primary malignant

Institute of Orthepedics and Traumatology, Faculty of Medicine, University of São Paulo

Email: olapcama@uol.com.br

Received for publication on July 30, 2005.

Accepted for publication on December 12, 2005. bone tumors in children. ${ }^{2}$

Until the mid-1970s, over $80 \%$ of patients affected by osteosarcoma would die within 5 years after being diagnosed. Ewing's sarcoma would progress, even with radiotherapic treatment, to $90 \%$ mortality. ${ }^{3}$ Amputation was the only option.

During the last 20 years, new knowledge and studies on bone sarcomas have been presented, and great advances in the treatment of these diseases have been achieved. ${ }^{4}$ Orthopedic surgical technology allows tumor resection while preserving the limb, because adequate resection margins reduce the probability of local tumor recurrence; ${ }^{5}$ moreover, modern prostheses preserve limb function. 
The use of chemotherapy before and after surgery for tumor removal (adjuvant and neoadjuvant chemotherapies) ${ }^{6}$ was developed to promote local control of the tumor by reducing its size. The Huvos index, which rates chemotherapy-induced tumor necrosis from $0 \%$ to $100 \%$, emphasizes the importance of the degree of necrosis in the patient's prognosis. ${ }^{7,8}$

Radiotherapy is used in those cases of Ewing's sarcomas where, due to their locations, resection is impracticable, when tumor margins are affected as well as in cases where surgery would impair the function of the limb. Improvement in image evaluations and current chemotherapy regimens have contributed significantly to the detection and systemic control of the disease. ${ }^{9}$

Cooperation between oncologists, pathologists, radiologists, and orthopedic surgeons with specialized knowledge of oncology allows more effective detection and therapy of bone tumors. ${ }^{1,3,4,10-15}$

In diagnosing a bone neoplasm, attention should be paid to early signs and symptoms in order to distinguish it from other orthopedic conditions, such as osteomyelitis and tendonitis, and to distinguish different bone neoplasms from one another. ${ }^{11}$

An improvement in the 5-year survival rates from less than $10 \%$ to the current $50 \%$ to $60 \%$ has been reported for both osteosarcoma and Ewing's sarcoma. Some studies show 5 -year survival rates of up to $75 \%$ for patients with these 2 tumors. ${ }^{3,16}$

However, this improvement is only possible with early diagnosis of the tumor. The prognosis of osteosarcoma and Ewing's sarcoma is mainly influenced by the local extent of the tumor and by the presence of metastases. ${ }^{17}$ Chances of survival decrease 2 to 3 times in the presence of metastases. ${ }^{17,18}$ American and European statistics show that diagnosis is made between 1 and 3 months after first presentation with symptoms. In Brazil, although no research has covered this subject, a consensus exists that definitive diagnosis of a bone neoplasm takes, on average, 6 months after the onset of symptoms. ${ }^{1,19}$ In many cases, the treatment is started when the tumor has already achieved a large volume, which so that local control becomes difficult, hindering surgery with preservation of the limb, with a reduced chance of cure.In spite of the large number of trials on prognostic factors in oncology, many of them have little impact on the clinical practice..$^{20}$ In Brazil, there have been no clinical trials to corroborate the interval between the onset of signs and symptoms and the definitive diagnosis nor any that attribute adequate importance to these early signs and symptoms, even though the need for early diagnosis of the tumor has been proven.

The purpose of this project is to show that it is neces- sary to reduce the interval between the onset of signs and symptoms and the diagnosis of cases of osteosarcoma and Ewing's sarcoma in Brazil, thus increasing the chances of survival for these patients. For this, it is essential that physicians be aware of the characteristic early signs and symptoms, such as pain, increase of local volume, fever, and in some cases, the original pathological fracture.

An analysis of the signs and symptoms presented originally by patients diagnosed with osteosarcoma and Ewing's sarcoma and a comparative evaluation of the interval between the onset of signs and symptoms and the definitive diagnosis in these tumors are needed.

\section{CASES AND METHODS}

A retrospective analysis was performed on the medical dossiers of patients in the Orthopedic Oncology Group of this institution who were diagnosed with osteosarcoma and Ewing's sarcoma between 1985 and 2001. Approximately 365 patients aged 30 years or under at the time of diagnosis based on the histological analysis of biopsy material were considered for this study. All of them were or continued to be continued to be treated in this hospital. Of the 365 patients, 250 medical dossiers that included complete, properly referenced data were selected.

The data collected from each medical dossier was organized on a standard form the purpose of which was not only to record the patient's symptoms (such as pain, fever, and volume increase, as well as the blood count and previous trauma), but also to record the main events that involved the patient during the treatment period (such as biopsy, surgery, use of neoadjuvant chemotherapy, metastases, and current orthopedic and oncologic condition).

Obtained data was organized for statistical analysis into 2 groups according to the type of tumor presented. The absolute and relative percentage frequency distributions of the normal (qualitative) parameters were determined, as well as were the descriptive statistics of the following ordinal (quantitative) parameters: mean (M), standard deviation (SD), standard error of the mean (SEM), maximum and minimum values, and number of cases $(\mathrm{N})$.

To compare the frequency distributions of nominal parameters between the groups (the osteosarcoma group and the Ewing's sarcoma group) we used 2-sample methods, such as the chi-square, binomial, Fisher, and McNemar tests; to compare the means of the ordinal samples, we used either Student's $t$ test or the Mann-Whitney U test (for parametric and nonparametric distributions, respectively). The $5 \%$ significance level $( \pm=0.05)$ was adopted.

The case study included the type of tumor, age, and place affected by the disease in each patient, as well as the 
main signs and symptoms presented in diagnosing osteosarcoma or Ewing's sarcoma. The time interval between the onset of signs and symptoms and diagnosis was correlated for each group throughout the period studied (1985 through 2001) and between groups.

\section{RESULTS}

A descriptive statistical analysis of patients' ages was performed after they were divided into 2 groups according to the type of tumor (Table 1). The evaluation showed that the mean age when an osteosarcoma occurred was 15.7 years, while for Ewing's sarcoma the mean age of occur-

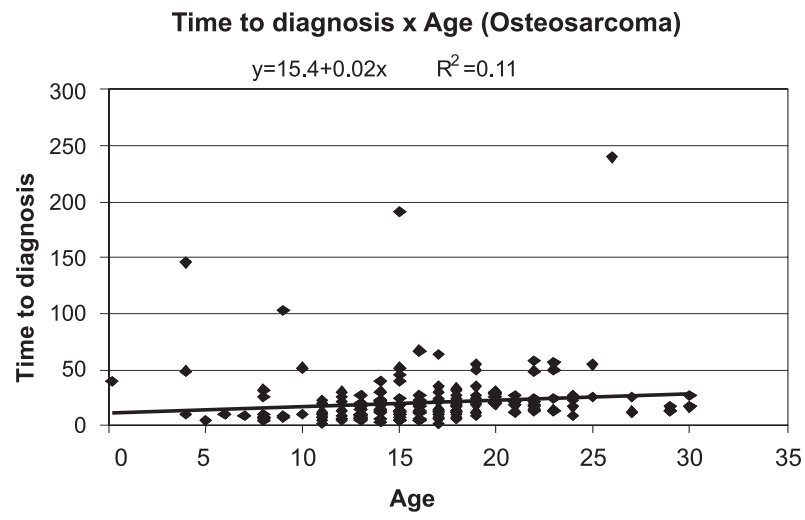

Time to diagnosis $x$ Age (Ewing's sarcoma)

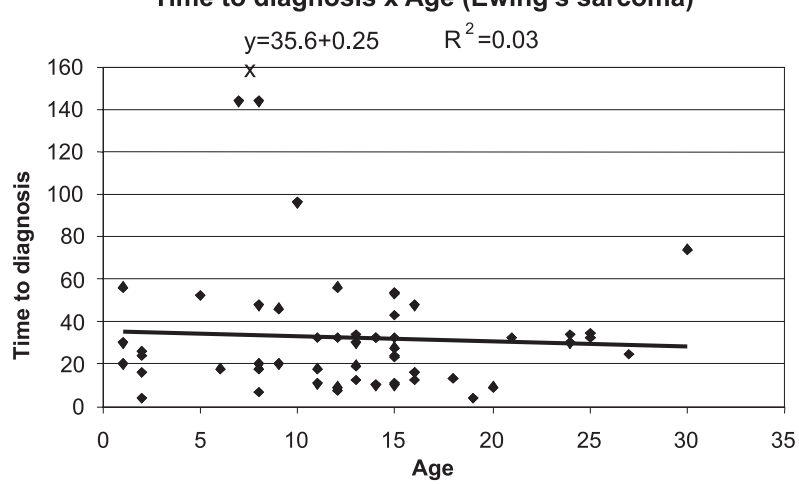

Figure 1 - Comparative analysis of patients' age and the time to diagnosis of patients with Osteosarcoma and Ewing's Sarcoma. Comparison using a two-tailed Mann-Whitney U-test $( \pm=0.05)$ rence was 12.8 years. The comparative analysis of both groups using Mann-Whitney $U$ test showed that the difference between ages was significant, with $P=0.0005$ and percentage variation of $19 \%$. Thus patients with Ewing's sarcoma tended to be 2.9 years younger than patients with osteosarcoma on the dates they were diagnosed. The comparative analysis between the patient's age and the time of diagnosis, using the Mann-Whitney $U$ test, did not show any correlation for either patients with osteosarcoma $(P=$ $0.11)$ or for patients with Ewing's sarcoma $(P=0.66)$; therefore, the patient's age appeared to have no influence on the time until diagnosis of these tumors (Figure 1).

The descriptive analysis of the time from onset of symp-

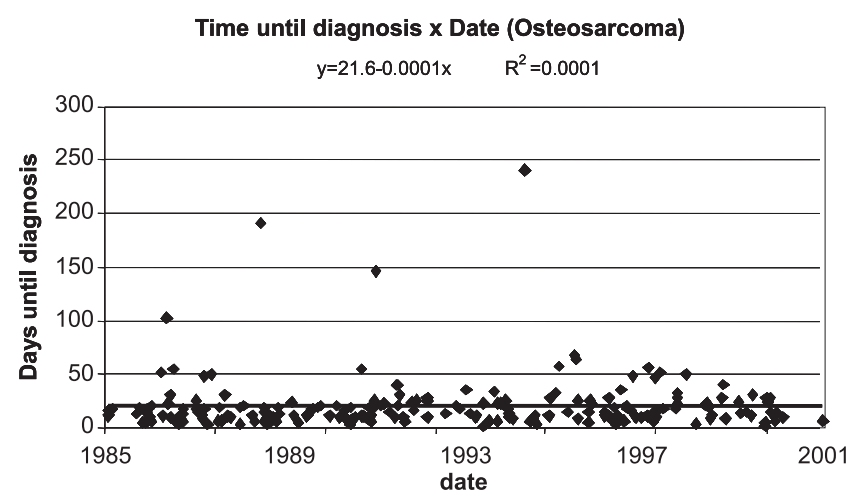

Time until diagnosis $\times$ Date (Ewing's sarcoma)

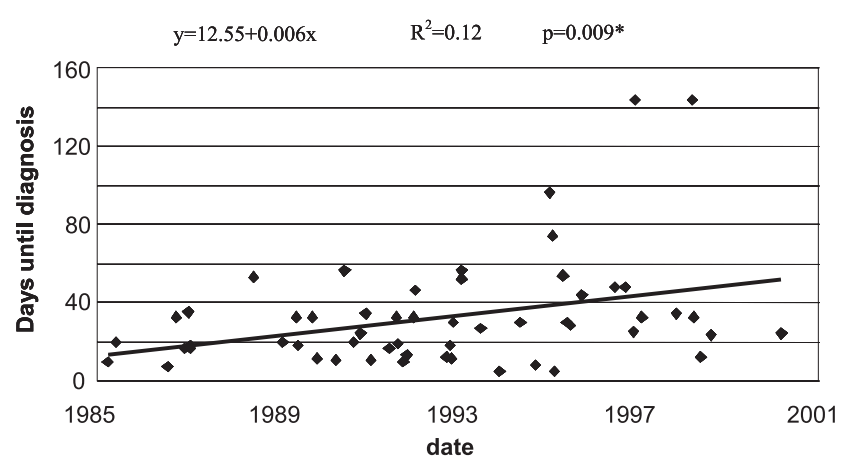

Figure 2 - Comparative analysis of the time until diagnosis and date of diagnosis in patients with Osteosarcoma and Ewing's Sarcoma. Comparison using a two-tailed mann-whitney u-test $( \pm=0.05)$

Table 1 - Descriptive statistics of patients' age and time to diagnosis in the Osteosarcoma and Ewing's Sarcoma groups. Comparison using a two-tailed Mann-Whitney u-test $( \pm=0.05)$

\begin{tabular}{lcc}
\hline & AGE $($ YEARS $)$ & WEEKS TO DIAGNOSIS \\
\hline OSTEOSARCOMA & Mean \pm SEM: $15.8 \pm 0.4$ & Mean \pm SEM: $21.2 \pm 1.8$ \\
$(\mathrm{~N}=198)$ & minimum: 0.2 maximum: 30 & minimum: 1 maximum: 240 \\
EWING'S SARCOMA & Mean \pm SEM: $12.8 \pm 0.9$ & Mean \pm SEM: $32.4 \pm 3.8$ \\
$(\mathrm{~N}=55)$ & minimum: 1 maximum: 30 & minimum: 4 maximum: 144 \\
$\mathrm{P}$ (Mann-Whitney) & $\mathrm{p}=0.0005$ & $\mathrm{p}=0.0001$ \\
\hline
\end{tabular}

SEM: standard error of the mean; Min/Max: minimum/maximum time of occurrence 
toms until diagnosis was performed for the osteosarcoma and Ewing's sarcoma groups. It was found that in this service, the average time until diagnosis was 21.1 weeks for osteosarcoma, while for Ewing's sarcoma the average time until diagnosis was 32.4 weeks (Table 1).

A descriptive analysis was performed on the distribution of the sites affected by the tumor according to the osteosarcoma and Ewing's sarcoma groups. The analysis showed a difference in the distribution pattern between the tumors: osteosarcoma tended to affect the distal portion of the femur, the proximal portion of the tibia, fibula and humerus and, less frequently, the pelvis or other parts of the body, whereas Ewing's sarcoma had a more homogeneous distribution in the femur and tibia portions and more commonly affected the distal portion of the fibula, in addition to more frequently affecting the pelvis and other regions of the body (such as the spine) (Table 2).

Table 2 - Absolute and relative frequency distribution (\%) of sites affected by Osteosarcoma or Ewing's Sarcoma in both groups, and intergroup comparison using a two-tailed chi-square test $(\alpha=0.05)$

\begin{tabular}{lllll}
\hline \multirow{2}{*}{ SITE } & \multicolumn{2}{l}{ OSTEOSARCOMA } & \multicolumn{2}{l}{ EWING'S } \\
& $\mathrm{n}$ & $\%$ & $\mathrm{l}$ SARCOMA \\
& & $\mathrm{n}$ & $\%$ \\
\hline proximal femur & 12 & 6.42 & 8 & 15.69 \\
Diaphyseal femur & 6 & 3.21 & 8 & 15.69 \\
distal femur & 83 & 44.39 & 6 & 11.76 \\
Fêmur & 101 & 54.01 & 22 & 43.14 \\
proximal fibula & 7 & 3.74 & 0 & 0 \\
diaphyseal fibula & 1 & 0.53 & 1 & 1.96 \\
distal fibula & 1 & 0.53 & 3 & 5.88 \\
Fibula & 9 & 4.81 & 4 & 7.84 \\
proximal tibia & 42 & 22.46 & 7 & 13.73 \\
diaphyseal tibia & 0 & 0 & 1 & 1.96 \\
distal tibia & 9 & 4.81 & 3 & 5.88 \\
Tibia & 51 & 27.27 & 11 & 21.57 \\
proximal humerus & 14 & 7.49 & 1 & 1.96 \\
diaphyseal humerus & 2 & 1.07 & 0 & 0 \\
distal humerus & 2 & 1.07 & 0 & 0 \\
Humerus & 18 & 9.63 & 1 & 1.96 \\
Pelvis & 2 & 1.07 & 3 & 5.88 \\
Others & 6 & 3.21 & 10 & 19.61 \\
TOTAL & 187 & 100 & 51 & 100 \\
\hline & & & & \\
\hline
\end{tabular}

The elevated frequency of osteosarcoma of the distal femur and of sarcoma of the proximal tibia (the knee region) led us to analyze the distribution of these tumors per region of the body. The absolute and relative frequencies (Figure 3 and Table 3) were described and showed that osteosarcoma would affect predominantly the knee, with lower frequencies in the hip, shoulder, and ankle. Ewing's sarcoma affected the knee and hip with similar relative frequencies that are somewhat lower in the ankle and higher

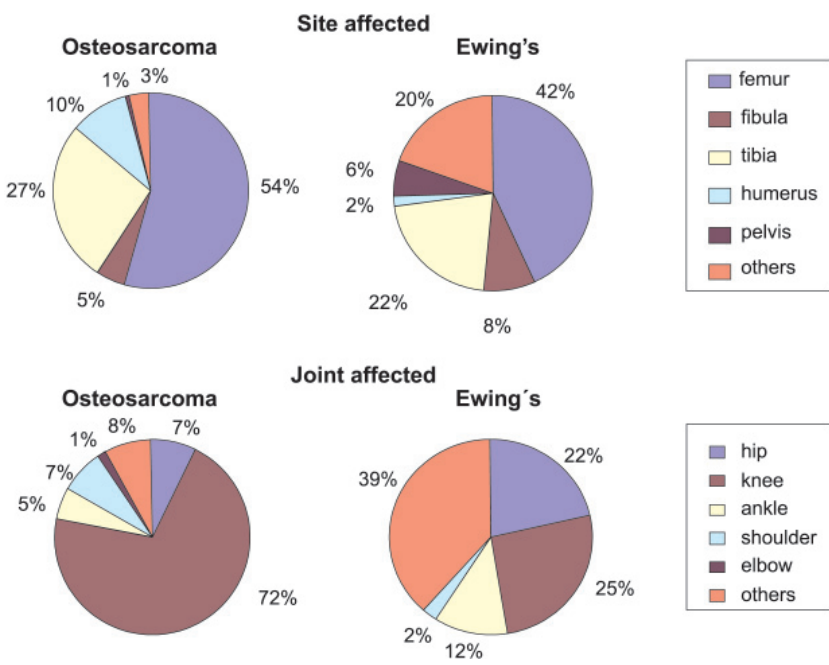

Figure 3 - Absolute and relative frequency distribution of bone sites and joints affected by tumor in patients with Osteosarcoma and Ewing's sarcoma

Table 3 - Absolute and relative frequency distribution (\%) of sites affected by Osteosarcoma or Ewing's Sarcoma, by joint involved, and intergroup comparison using a two-tailed chi-square test $(\alpha=0.05)$

\begin{tabular}{|c|c|c|c|c|}
\hline \multirow[t]{2}{*}{ SITE } & \multicolumn{2}{|c|}{ OSTEOSARCOMA } & \multicolumn{2}{|c|}{$\begin{array}{l}\text { EWING'S } \\
\text { SARCOMA }\end{array}$} \\
\hline & $\mathrm{N}$ & $\%$ & $\mathrm{~N}$ & $\%$ \\
\hline proximal femur & 12 & 6.42 & 8 & 15.69 \\
\hline Pélvis & 2 & 1.07 & 3 & 5.88 \\
\hline Hip & 14 & 7.49 & 11 & 21.57 \\
\hline distal fêmur & 83 & 44.39 & 6 & 11.76 \\
\hline proximal tibia & 42 & 22.46 & 7 & 13.73 \\
\hline proximal fibula & 7 & 3.74 & 0 & 0 \\
\hline Knee & 132 & 70.59 & 13 & 25.49 \\
\hline distal fíbula & 1 & 0.53 & 3 & 5.88 \\
\hline distal tíbia & 9 & 4.81 & 3 & 5.88 \\
\hline Ankle & 10 & 5.35 & 6 & 11.76 \\
\hline proximal humerus & 14 & 7.49 & 1 & 1.96 \\
\hline Shoulder & 14 & 7.49 & 1 & 1.96 \\
\hline distal humerus & 2 & 1.09 & 0 & 0 \\
\hline Elbow & 2 & 1.07 & 0 & 0 \\
\hline diaphyseal tibia & 0 & 0 & 1 & 1.96 \\
\hline diaphyseal humerus & 2 & 1.07 & 0 & 0 \\
\hline diaphyseal femur & 6 & 3.21 & 8 & 15.69 \\
\hline diaphyseal fibula & 1 & 0.53 & 1 & 1.96 \\
\hline Others & 6 & 3.21 & 10 & 19.61 \\
\hline others/total & 15 & 8.02 & 20 & 39.22 \\
\hline TOTAL & 187 & 100 & 51 & 100 \\
\hline
\end{tabular}

in other joints other than the above-mentioned ones (such as the spine) and diaphyseal portions of bones.

The chi-square method was used to analyze the absolute and relative (\%) frequency of early signs and symptoms of patients after dividing them into 2 groups according to the type of tumor.

Since the study of fracture frequency, pain frequency, 
and pain at rest frequency did not show any difference between the tumor types $(P=0.53 ; P=0.49 ; P=0.52$, respectively), these signs cannot be used as a differential in the diagnosis of these tumors (Table 4).

The study of fever frequency showed a difference between the tumor types $(P=0.002)$; therefore, fever may be used as a factor in the differential diagnosis of these tumors (Table 4).

The study of weight loss frequency did not show any difference between the tumor types $(P=0.93)$; therefore, weight loss cannot be used as a differential in the diagnosis of these tumors (Table 4).

The study of the local volume increase frequency showed a difference between the tumor types $(P=0.015)$, with an inversion of values in the chi-square table (Table 4); therefore, early increase in local volume may be used to aid in the differential diagnosis.

A comparative analysis using Student's $t$ test and the Mann-Whitney $\mathrm{U}$ test between the 2 groups (osteosarcoma and Ewing's sarcoma groups) concerning the time interval between the onset of signs and symptoms and the date of diagnosis of patients showed a difference between the groups $(P<0.0001,34.9 \%$ variation), showing that on average it took 11.3 weeks longer before for Ewing's sarcoma was diagnosed.

Although the time from the onset of signs and symptoms until diagnosis throughout the period analyzed (1985 though 2001) was not significantly diffenent for patients with osteosarcoma (Figure 2), this value was significantly longer over time $(P=0.009)$ for patients with Ewing's sarcoma (Figure 2).

\section{DISCUSSION}

This study is part of an institutional effort to retrospectively summarize some of our most significant patient series. ${ }^{21-23}$ The increased length of time until diagnosis of tumors in Brazil as compared with that reported for the US and Europe (where it takes on average 4 to 12 weeks to reach a definitive diagnosis) is not surprising. However, this study provides statistical confirmation of a delay that should not occur in the case of malignant tumors requiring early diagnosis in order to allow a potentially healing treatment for patients. This 11-week difference remains to be explained, although possibilities include a lack of awareness on the part of patients of early signs and symptoms that might cause a delay in seeing a physician or, more importantly, errors concerning differential diagnosis made by the physician who sees this patient at onset of the condition.

The finding that in recent years the delay of diagnosis of Ewing's sarcoma has increased in our service should be discussed. Possible explanations include, among others, the following: the patient delayed his visit to a physician; the health system took too long to schedule a medical appointment, both in basic health units and outsourced hospitals; errors occurred in the differential diagnosis in a primary

Table 4 - Absolute and relative frequency distribution (\%) of fracture, pain, pain at rest, fever, weight loss and local volume increase as early symptoms of patients in the Osteosarcoma and Ewing's Sarcoma groups, and intergroup comparison using a two-tailed chi-square test ( $\pm=0.05$ )

\begin{tabular}{|c|c|c|c|c|c|c|c|}
\hline & \multirow[t]{2}{*}{ CHI-SQUARE(probability) } & \multicolumn{2}{|c|}{ OSTEOSARCOMA } & \multicolumn{2}{|c|}{ EWING'S SARCOMA } & \multicolumn{2}{|c|}{ TOTAL } \\
\hline & & $\mathrm{N}$ & $\%$ & $\mathrm{~N}$ & $\%$ & $\mathrm{~N}$ & $\%$ \\
\hline \multicolumn{8}{|l|}{ FRACTURE } \\
\hline ABSENCE & $0.39(\mathrm{p}=0.53)$ & 175 & 70.3 & 50 & 20.1 & 225 & 90.4 \\
\hline PRESENCE & & 20 & 8.0 & 4 & 1.6 & 24 & 9.6 \\
\hline \multicolumn{8}{|l|}{ PAIN } \\
\hline ABSENCE & $0.47(\mathrm{p}=0.49)$ & 19 & 7.6 & 7 & 20.1 & 26 & 10.4 \\
\hline PRESENCE & & 176 & 77.7 & 47 & 18.9 & 223 & 89.6 \\
\hline \multicolumn{8}{|c|}{ PAIN AT REST } \\
\hline ABSENCE & $0.42(\mathrm{p}=0.52)$ & 179 & 71.9 & 51 & 20.5 & 230 & 92.4 \\
\hline PRESENCE & & 16 & 6.4 & 31.2 & & 19 & 7.6 \\
\hline \multicolumn{8}{|l|}{ FEVER } \\
\hline ABSENCE & $9.41(\mathrm{p}=0.002)^{*}$ & 188 & 75.5 & 46 & 18.5 & 234 & 94.0 \\
\hline PRESENCE & & 7 & 2.8 & 8 & 3.2 & 15 & 6.0 \\
\hline \multicolumn{8}{|c|}{ WEIGHT LOSS } \\
\hline ABSENCE & $0.07(\mathrm{p}=0.93)$ & 167 & 67.1 & 46 & 18.5 & 213 & 85.6 \\
\hline PRESENCE & & 28 & 11.2 & 8 & 3.2 & 36 & 14.4 \\
\hline \multicolumn{8}{|c|}{ VOLUME INCREASE } \\
\hline ABSENCE & $5.86(\mathrm{p}=0.015)^{*}$ & 76 & 30.5 & 31 & 12.4 & 107 & 43.0 \\
\hline PRESENCE & & 119 & 47.8 & 23 & 9.2 & 142 & 57.0 \\
\hline TOTAL & & 195 & 78.3 & 54 & 21.7 & 249 & 100.0 \\
\hline
\end{tabular}


health center; there was a delay in referring the patient to a specialty service; or there was an erroneous differential diagnosis or delay in performing the biopsy due to demand that exceeded the capacity of the surgical center.

We originally proposed to study the time from onset of signs and symptoms until the diagnosis according to 3 categories: (1) the time from the onset of signs and symptoms until the first visit to a physician, often in a primary health center; (2) the time from the first visit to a physician until the first visit to a bone tumor specialty service, in this case, our institution; (3) the time from the first visit to our institution and the date of diagnosis, based on the biopsy report. The information obtained could indicate the reasons for delay or the moments when the diagnosis of osteosarcoma and Ewing's sarcoma took more time, suggesting actions for reducing this problem. It was not possible to perform such analyses because there was not a statistically significant number of patients with medical dossiers including all information required, such as the date of the first visit; the initial symptoms and their onset dates; the date when the patient was referred to a specialty service; the date of the patient's first visit to our service; or the evolution of the patient's clinical condition. While this project was being performed, it was seen that basic questions of anamnesis, such as the patient's complaint and its length, were often ignored in the patient's medical dossier, which rarely would mention the patient's previous history of medical visits. Many explanations are possible: in some cases, the patient presented in our institution with the diagnosis either confirmed or questioned by another service; or, due to the advanced degree of evolution of the disease, the physician already had in mind the diagnosis of a probable tumor. Thus, during the initial anamnesis in our service, the main questions focused on possible complications of the tumor. It is also valid to think that, due to the high volume of visits, the physician in charge tried to simplify the description of the visit in the dossier, so some data, although elicited, was not reported.

Nevertheless, such explanations do not justify incomplete documentation that is official in character, as is the case of the medical dossier, and suggest that the medical visit was deficient. We have focused attention on these factors because as long as there is not enough information available, it will not be possible determine the source of the greatest delay for a patient in the public health service. Therefore, it was not possible to determine the cause of the difference in the time until diagnosis between this service and the American and European experiences; nor was it possible to explain why the Ewing's sarcoma diagnosis was increasingly delayed over time.
Formulating public intervention policies for these tumors based on this data would be risky. ${ }^{24}$ However; this study identifies several early signs and symptoms that could be used to alert patients and physicians to the possibility of osteosarcoma or Ewing's sarcoma. Additionally early indications regarding differential diagnosis between the two tumor types, were identified. Fever may be used judiciously in the differential diagnosis. Since fever is present more frequently in Ewing's sarcoma, its presence may indicate the presence of this tumor; however, its absence does not point to osteosarcoma, given that fever alone was not very frequent in either tumor type.An increase in local volume may be used as a factor in the differential diagnosis of these tumors. Patients with osteosarcoma had a $38.6 \%$ higher probability of presenting volume increase as an early symptom than patients with Ewing's sarcoma (Table 4).

Publication for the lay public in general and for medical professionals in particular of the most common early signs and symptoms, the mean age at the onset, and the body regions most frequently affected in the osteosarcoma and Ewing's sarcoma may serve as an alert for the possibility of bone cancer, stimulating patients to see a physician without undue delay, as well as guiding physicians to more quickly refer a patient to a specialized service for correct diagnosis and treatment. This type of education could help minimize the delay in diagnosing these tumors.

\section{CONCLUSIONS}

1. Patients with Ewing's sarcoma are younger (mean age: 12.8 years) than those with osteosarcoma (mean age: 15.7 years).

2. Patients with osteosarcoma or Ewing's sarcoma present local pain most frequently ( $89.5 \%$ of the time) as an early symptom. Besides pain, local pain at rest, weight loss, and pathological fracture occur in these tumors in equal proportions.

3. Patients with osteosarcoma present volume increase more frequently, while those with Ewing's sarcoma present fever more frequently.

4. The time interval between the onset of signs and symptoms and diagnosis observed for osteosarcoma in our service was, on average, 21.12 weeks (5.25 months), while for Ewing's sarcoma it was 32.4 weeks (8.1 months).

5. The time until diagnosis for either tumor was higher than that reported for North America or Europe.

6. The time until diagnosis for Ewing's sarcoma had increased in our service between 1985 and 2001. 
Guerra RB, Tostes MD, Miranda L da C, de Camargo OP, Baptista AM, Caiero MT. Análise comparativa entre Osteossarcoma e Sarcoma de Ewing: avaliação do intervalo de tempo entre o início dos sinais e sintomas e o diagnóstico. Clinics. 2006;61(2):99-106.

FINALIDADE: Eeste estudo propõ-se a esclarecer as características do osteossarcoma e do sarcoma de Ewing, bem como definir o intervalo de tempo decorrido, no Brasil, entre o início dos sinais e dos sintomas e o diagnóstico definitivo, fornecendo subsídios para um diagnóstico precoce desses tumores.

MÉTODO: Alguns aspectos dos diagnósticos clínicos do prontuário de 365 pacientes com menos de 30 anos de idade, portadores de osteossarcoma ou sarcoma de Ewing foram analisados de forma retrospectiva e comparativa, seguindo-se uma análise estatística.

RESULTADOS: O tempo entre o início de sinais e sintomas e o diagnóstico foi de 5,25 meses no osteossarcoma e 8,1 meses no sarcoma de Ewing; o sintoma mais freqüente $(89,5)$ nas duas neoplasias foi a dor localizada. CONCLUSÃO: O tempo para o diagnóstico de ambas as neoplasias é maior do que o observado em estatísticas norte-americanas e européias.

UNITERMOS: Sarcoma de Ewing. Osteossarcoma. Neoplasias ósseas. Quimioterapia. Cirurgia ortopédica.

\section{REFERENCES}

1. Camargo OP, Croci AT. Diagnóstico e tratamento dos sarcomas ósseos de alta malignidade. Rev Diag Tratamento. 1999;4:20-5.

2. Yaw KM. Pediatric bone tumors. Semin Surg Oncol. 1999;16:173-83.

3. Malawer MM, Link MP, Donaldson SS. Sarcomas of bone. In: Devita VT Jr, Hellman S, Rosenberg SA, editors. Cancer: principles and practice of oncology. Philadelphia: Lippincott; 1993. p. 1509-60.

4. Vlasak R, Sim FH. Ewing's sarcoma. Orthop Clin North Am. 1996;27:591-603.

5. Sluga M, Windhager R, Lang S, Heinzl H, Krepler P, Dkus M, et al. The role of surgery and resection margins in the treatment of Ewing's sarcoma. Clin Orthop. 2001;392:394-9.

6. Tabone MD, Terrier P, Pacquement H, Brunat-Mentigny M, BabinBoilletot A, Mahmoud HH, et al. Outcome of radiation-related osteosarcoma after treating childhood and adolescent cancer: a study of 23 cases. J Clin Oncol. 1999;17:2789-95.

7. Picci P, Bohling T, Bacci G, Ferrari S, Sangiorgi L, Mercuri M, Manfrini $\mathrm{M}$, et al. Chemotherapy-induced tumor necrosis as a prognostic factor in localized Ewing's sarcoma of the extremities. J Clin Oncol. 1997;15:1553-9.

8. Bacci G, Ferrari S, Bertoni F, Rimondini S, Longhi A, Bacchini F, et al Prognostic factors in nonmetastatic Ewing's sarcoma of bone treated with adjuvant chemotherapy: analysis of 359 patients at the Istituto Ortopedico Rizzoli. J Clin Oncol. 2000;18:4-11.
9. Hansmann HJ, Wunsch C, Darge K, Schneider B, Hess T, GruberHoffmann B, et al. Diagnostic imaging for therapy control of primary bone tumors. Radiologe. 1998;38:523-9.

10. Dominkus M, Kainberger F, Lang S, Kotz, R. Primary malignant bone tumors. Clinical aspects and therapy. Vienna Bone Tumor Registry. Radiologe. 1998;38:82.

11. Widhe B, Widhe T. Initial symptoms and clinical features in osteosarcoma and Ewing sarcoma. J Bone Joint Surg Am. 2000;82:66774.

12. Costa CML, Mendes WL, Alves L, Penna V. Tumores ósseos. In: Camargo B, Lopes LF, editors. Pediatria oncológica: noções fundamentais para o pediatra. Sao Paulo: Lemar; 2000. p. 161-73.

13. Horowitz ME, Malawer MM, Woo SY, Hicks JM. Ewing's sarcoma family of tumors: Ewing's sarcoma of bone and soft tissue and the peripheral primitive neuroectodermal tumors. In: Pizzo PA, Poplack DG, editors. Principles and practice of pediatric oncology. Philadelphia: Lippincott/Raven; 1997. p. 831-63.

14. Bondar IV, Durnov LA, Lebedev VI, Goldobenko GV, Koshechkina NA, Pashkov IV, et al. Metastatic lung tumors in children. Vopr Onkol. 2000;46:446-8.

15. Link MP, Eilber F. Osteosarcoma. In: Pizzo PA, Poplack DG, editors. Principles and practice of pediatric oncology. Philadelphia: Lippincott/ Raven; 1997. p. 889-920. 
16. Exner GU, Von Hoscstetter AR, Schreiber A, Sokolovic-Dalipagic E. Osteosarcoma and Ewing's sarcoma. Improved recovery chances in the past 25 years according to the experience of Balgrist Hospital. Schwinz Rundsch Med Prax. 1996;85:706-13.

17. Ferrari S, Bertoni F, Mercuri M, Sottili S, Versari M, Bacci G. Ewing's sarcoma of bone: relation between clinical characteristics and staging. Oncol Rep. 2001;8:553-6.

18. Cotterill SJ, Ahrens S, Paulussen M, Jurgens HF, Voute PA, Gadner H, et al. Prognostic factors in Ewing's sarcoma of bone: analysis of 975 patients from the European Intergroup Cooperative Ewing's Sarcoma Study Group. J Clin Oncol. 2000;18:3108-14.

19. Lang S, Sulzbacher I. Special diagnostic problems in primary malignant bone tumors. Radiologe. 1998;38:458-66.

20. Bentzen SM. Prognostic factor studies in oncology: osteosarcoma as a clinical example. Int J Radiat Oncol Biol Phys. 2001;49:513-8.
21. Etchebehere M, Camargo OP, Croci AT Oliveira CRCM, Batista AM Relationship between surgical procedure and outcome for patients with grade I chondrosarcomas. Clinics. 2005;60:121-126.

22. Camargo OP de, Croci AT, Oliveira CRGMC de, Baptista AM, Caiero MT. Functional and radiographic evaluation of 214 aggressive benign bone lesions treated with curettage, cauterization, and cementation: 24 years of follow-up. Clinics. 2005;60:439-444.

23. Vaz CES, Camargo OP de, Santana PJ de, Valezi AC. Accuracy of magnetic resonance in identifying traumatic intraarticular knee lesions. Clinics. 2005;60:445-450.

24. Sneppen O, Hansen LM. Presenting symptoms and treatment delay in osteosarcoma and Ewing's sarcoma. Acta Radiol Oncol. 1984;23:15962. 